\title{
ESCOLA, FAMÍLIA, INFÂNCIA E FANTASIA: CRIANÇAS E ADULTOS CONSTRUINDO VÍNCULOS DE CONFIANÇA
}

Tony Aparecido Moreira, Denise Watanabe, José Milton de Lima, Márcia Regina Canhoto de Lima

Universidade Estadual Paulista - UNESP, Departamento de Educação, Presidente Prudente - SP. E-mail: tony.educ@gmail.com. Agência financiadora: CAPES.

\section{RESUMO}

Esta pesquisa surgiu a partir da necessidade de ampliação dos saberes acerca do imaginário infantil por professores, pais e responsáveis, assim como a aproximação entre esses adultos e as crianças. O estudo foi desenvolvido em duas instituições de Educação Infantil do oeste paulista dentro de uma investigação sobre a fantasia das crianças. A pesquisa teve como objetivo principal a construção de vínculos de confiança entre os adultos e crianças investigados por meio do desenvolvimento de jogos de fantasia e atividades de aproximação entre os sujeitos. A investigação-ação foi a metodologia utilizada, como modo de garantir o desenvolvimento de brincadeiras e jogos de fantasia, assim como a implementação de um processo de investigação da própria prática para qualificação da abordagem pedagógica das professoras e da relação dos pais e responsáveis com as crianças. A Sociologia da Infância e os estudos de Paul L. Harris foram os principais referenciais teóricos desta investigação, tendo em vista o conceito de criança como sujeito social de estatuto próprio e a imaginação como uma linguagem humana primordial, desenvolvida ao longo de toda a vida humana. Os dados foram coletados por meio de um estreito acompanhamento das crianças das turmas de Educação Infantil das duas instituições investigadas, uso de gravadores, câmera de imagem e vídeo, entrevistas e diários de campo. Identificamos, sobretudo, que houve a qualificação das relações entre os adultos e as crianças participantes e que esta aproximação foi benéfica para todos os sujeitos. Esperamos contribuir com outros estudos e convencer sobre a pertinência do tema.

Palavras-chave: Fantasia; Sociologia da Infância; Educação Infantil; Imaginação na Infância; Adultos e Crianças.

\section{SCHOOL, FAMILY, CHILDHOOD AND FANTASY: CHILDREN AND ADULTS BUILDING BONDS OF TRUST THROUGH THE TO PLAY AND TO FANTASIZE H}

\begin{abstract}
This research arose from the need to increase knowledge about the child's imagination by teachers, parents and guardians, as well as the rapprochement between these adults and children. The study was developed in two childhood education institutions in western São Paulo in an investigation into the fantasy of children. The research aimed to build bonds of trust between adults and children investigated through the development of fantasy games and outreach activities among the subjects. The research-action was the methodology used, as a way to ensure the development of games and fantasy games, as well as the implementation of a process of own practice research for qualification of the pedagogical approach of the teachers and the relationship of parents and caregivers with children. The sociology of childhood and studies of Paul L. Harris were the main theoretical framework of this research, in view of the child's concept as a social subject of separate status and the imagination as a primary human language, developed over all human life. Data were collected through close monitoring of children from Early
\end{abstract}


Childhood classes of both institutions investigated, use recorders, imaging camera and video, interviews and field diaries. Identified above all there was the qualification of relations between adults and children participating and that this approach was beneficial for all subjects. We hope to contribute with other studies and convince the relevance of the topic.

Key words: Fantasy; Sociology of Childhood; Childhood Education; Imagination in Childhood; Adults and Children. 


\section{INTRODUÇÃO}

Esta pesquisa consiste em uma investigação-ação realizada em duas instituições de Educação Infantil do oeste paulista. O estudo surgiu a partir da constatação de que a linguagem imaginativa das crianças não era bem compreendida e valorizada pelos sujeitos das duas diferentes instituições. Esse dado repercutiu no desenvolvimento de uma investigação específica sobre o imaginário infantil, dentro esta pesquisa surgiu como um recorte, em decorrência da necessidade da aproximação de adultos e crianças, sobretudo, a construção de vínculos de confiança não somente entre alunos e professores, mas entre as crianças $e$ todos os adultos envolvidos em seus processos de escolarização, nesse sentido os adultos da escola e os do lar. Professoras, diretoras, pais e responsáveis foram convidados à mergulhar no universo infantil pela janela da imaginação.

As crianças foram as próprias precursoras do presente estudo a partir de uma pesquisa anterior, durante a qual aos seus modos denunciaram que suas fantasias ocupavam um espaço marginal em suas instituições, demonstrando a carência de uma abordagem mais valorativa do imaginário infantil, fato percebido também pelas professoras que alegavam que seus processos de formação não possibilitaram saberes ou caminhos sólidos para contribuir com o desenvolvimento da imaginação na infância.

Desse modo, nossa entrada nas duas instituições ocorreu por meio de uma pesquisa-ação sobre o jogo e a brincadeira, em que essas atividades eram desenvolvidas com as crianças semanalmente em ambos os espaços, buscando contribuir para a melhoria das relações entre as professoras e os próprios pesquisadores com as culturas infantis. O estudo já estava sendo desenvolvido há mais de sete anos na instituição I e há mais de dois anos na Instituição II, o que possibilitou a construção de elos de cooperação entre o grupo de profissionais das instituições e os pesquisadores da universidade, sobretudo, vínculos de confiança estabelecidos com as crianças, que tinham apreço especial pelas atividades e aguardavam com ansiedade o dia de realização das intervenções dessa pesquisa-ação.

Um fato ocorrido durante essas intervenções foi primordial para o desenvolvimento de um estudo mais profundo sobre a temática das fantasias das crianças em instituições de Educação Infantil. Uma das crianças procurou sua professora para dizer-Ihe: “- Eu sou um super herói!" (DIÁRIO DE CAMPO, 2010). Esse menino demonstrava esperar uma atenção especial, contudo, sua professora sorriu artificialmente 
e antes de se distanciar dele disse-Ihe: “- $\mathrm{Ha}$ tá! Sei... agora vai fazer a atividade!" (DIÁRIO DE CAMPO, 2010). Para a professora como para outros o fato não tinha a mínima importância, já que era sabido que a criança estava fantasiando, mas para aquele menino era de suma importância que ela o escutasse e quem sabe o indagasse mais sobre sua fantasia, seria uma demonstração de interesse em dialogar com ele sobre suas histórias.

Depois de não ter encontrado um adulto interessado, aquele menino voltou para o seu lugar e continuou a brincar sozinho, então:

Aproximei-me dele e iniciei um diálogo: "Você é um super herói? - Sim! - Eu também sou um super herói! - Você é? - Sou! Você tem super poderes? - Nossa! Eu tenho um monte de super poderes!". Ao dizer isso, Ihe dei um tecido que estava sobre a caixa de brinquedos, com cuidado o fixei em seus ombros, coloquei um casaco sobre os meus ombros e saímos a voar, fomos "salvar a cidade", logo outras crianças juntaram-se a nós e a escola se transformou numa "liga da justiça”. Já no final da intervenção ele me perguntou quando iríamos voar novamente, enfrentar monstros e salvar pessoas, e eu the respondi que depois de viajar por outras cidades eu voltaria na próxima semana, ele sorriu e me abraçou (DIÁRIO DE CAMPO, 2010).

Assim como nós, aquele menino entendia que não havíamos enfrentado monstros de verdade, que não emanamos poderes e nem se quer saíamos da escola, mas a emoção era verdadeira e tornava tudo como um fato real. As perguntas que ressoavam por aqueles ares eram: Por que não escutar atenciosamente cada fala? Por que não propor outros desafios? Por que não viajar com elas? Uma inquietação intensa nos tomava sem trégua, muito precisava ser feito para diminuir a distância entre a abordagem pedagógica e os "outros mundos das crianças".

Durante as brincadeiras, as crianças dialogavam com seus pares sobre diversos assuntos, tanto dos seus contextos de vida como de reinos distantes. Percebemos que estas falas não eram bem valorizadas e que além da falta de escuta, as atividades deveriam ser mais motivadoras, desafiadoras, caprichadas na busca de apresentar a diversidade de elementos do mundo.

Era preciso suscitar um mergulho no universo imaginário infantil, compreendendo que não podemos negar as manifestações imaginativas das crianças ou simplesmente 
entender como uma fase que será superada ao longo do tempo, sem nada fazer para contribuir com seu desenvolvimento.

As professoras das duas instituições demonstravam interesse em contemplar o imaginário infantil em suas práticas de forma mais efetiva, com intencionalidade e conhecimento teórico, contudo, afirmavam não dominar os suportes teóricometodológicos, já que, não haviam estudado a imaginação infantil de forma específica, nem tão pouco entendido que é necessário manifestar uma preocupação especial para com essa capacidade humana. Essas profissionais já haviam se convencido de que as atividades desenvolvidas nas instituições poderiam ser mais significativas para as crianças se suas fantasias fossem mais valorizadas, percebiam que 0 ritmo "tradicional propedêutico" era sufocante tanto para as crianças como para elas, uma abordagem mais próxima do imaginário infantil parecia ser uma boa direção, contudo, elas sentiam a necessidade de uma maior experiência do "novo que lhes instigava", para que assim se sentissem mais seguras em renovar suas abordagens a partir da inquietação gerada.

De alguma maneira, as professoras tinham a ligeira impressão de que para construir uma abordagem pedagógica mais contemplativa das fantasias infantis era necessário ter habilidades especiais, domínios superiores as suas possibilidades, ou ainda, que poderiam perder o controle de suas práticas, deixando suas turmas em meio a uma aparente "bagunça", tendo que enfrentar a cobrança dos pais e responsáveis sobre o processo de aprendizagem e desenvolvimento das crianças. Esses fatos confirmaram os próprios relatos das professoras sobre a carência de saberes do imaginário infantil em suas formações iniciais, conhecimentos que Ihes renderiam maior confiança em implantar o novo. Em decorrência dessa falta e de outros fatores o jeito "convencional" de atuar parecia menos suscetível a problemas, aceitar outra possibilidade de atuação ressoava como um desafio cheio de riscos e sem garantias, entretanto, essa proposta foi parecendo cada vez mais necessária, e elas mesmas expressaram o desejo de aprofundar os saberes obtidos, de investigar suas práticas, de considerar as crianças e suas fantasias de maneira mais plena.

Além da necessidade de aprofundamento apresentada pelas professoras, consideramos o fato de que os pais e responsáveis também devem ser alcançados, esse fato ganhou visibilidade pelas próprias crianças que ao apresentar novas brincadeiras em casa, conquistaram a atenção dos pais e responsáveis, que ao perceberem a repercussão das atividades na vida das crianças entenderam a importância 
de não simplesmente autorizar a realização da pesquisa com seus filhos ou netos, mas também participar do estudo.

A participação dos pais e responsáveis na pesquisa representa ir além dos muros da escola, uma repercussão necessária para garantir práticas de respeito e valorização das crianças e suas fantasias, sendo a instituição escolar e o lar, espaços privilegiados de socialização. Podemos entender que:

Quanto mais próximos os modos de socialização familiar estiverem dos modos de socialização escolar, maior é a perspectiva de sucesso na escola. Mas se é possível verificar este movimento em direção à apropriação da cultura escolar pelas famílias, mais ela poderá propor formas de agrupamentos, de propostas e de práticas para a inclusão das crianças e criar processos educacionais que articulem as fronteiras das culturas familiares e das culturas escolares. Promover habilidades de viver em dois mundos, na interculturalidade, sem capitular frente às desigualdades sociais, pode sugerir mudanças na cultura escolar (BARBOSA, 2007, p. 1072).
Para subsidiar esta investigação que envolveu diferentes sujeitos, a Sociologia da Infância foi o principal referencial teórico desta investigação, pelo qual a criança é compreendida como sujeito social ativo e a infância como categoria social do tipo geracional. Esses conceitos são inovadores, tendo em vista o longo período de ocultação e silenciamento impostos às crianças. $\mathrm{Na}$ perspectiva desse campo do conhecimento, entendemos a fantasia infantil como um eixo estruturador das culturas da Infância (SARMENTO, 2004). A fantasia do real, de acordo com Sarmento (2004), consiste em uma forma de inteligibilidade e um dos alicerces das manifestações infantis. Por meio da fantasia a criança constrói sua visão de mundo e atribui significado aos elementos que encontra.

Em contraponto a visão da fantasia como fase, esta pesquisa contempla as contribuições do Professor Paul L. Harris (Universidade de Harvard), que faz parte da renovação no campo da Psicologia acerca da imaginação na infância. Nessa perspectiva, as fantasias infantis não representam simples fingimento ou adaptação, mas permitem que a criança participe de diálogos que vão muito além de seus horizontes imediatos e aprendam sobre todos os tipos de entidades reais, visíveis, invisíveis e metafísicas. Ainda, de acordo com Harris (2005), o pensamento imaginativo permite que a criança entenda os 
fenômenos de forma particular, mas não significa que as crianças sejam ilógicas. A fantasia não representa uma fase de irracionalidade a ser superada, a imaginação é uma linguagem primordial para o ser humano é desenvolvida ao longo de toda a vida humana.

Entendemos como linguagem imaginativa a multiplicidade e pluralidade do corpo em ação no mundo: o cantar, o dançar, o correr, o silenciar, etc. Já que, a criança vivencia o todo da experiência, são os adultos que se encarregam de fazer as separações. Desse modo, ampliar a experiência imaginativa não significa simplesmente desenvolver técnicas para mobilizar abstrações de forma específica, mas favorecer tempos e espaços, investir na materialidade que é primordial para a imaginação, possibilitar experiências significativas que corroborem com a liberdade experimental das crianças, que permitam que elas aprendam a estar na linguagem e a usufruir de seu poder inventivo. Nesse sentido, devemos garantir uma pedagogia para a imaginação no cotidiano da Educação Infantil, com a preocupação de compreender como as crianças aprendem a estar na linguagem pelas próprias crianças para ser mais íntima delas, uma pedagogia que:

[...] não separe a formação de cidadãostrabalhadores-poetas, gente que tenha razão e coração, é o que move a criação de uma pedagogia do imaginário. Pois, desde o início de sua história, o homem acrescentou à fabricação dos objetos um excedente que não era funcional, mas que estava ligado à forma e à decoração, isto é, à beleza e ao deleite que ela nos traz. A ação humana marcada por esse "para além" do concreto, do real pelo prazer, pela beleza é o que marcava a singularidade e a unicidade dos seres humanos e de suas obras (BARBOSA, 2005, p. 16).

Buscamos encontrar os meios para a construção dessa pedagogia do imaginário, valorizando a beleza do encontro junto aos sujeitos, o cruzamento das histórias, a compreensão do real como esse acontecimento entre nós e a imaginação como meio de ampliar as nossas possibilidades de estar em linguagem, de sermos, de fazermos, de encontrarmos sentido, de saltarmos, de irmos além. Para tal tarefa foi fundamental uma injeção de sonho, um despertar por meio de um intervir pautado no respeito que considera os sujeitos com suas diferenças, mas não se acomoda ao que se enxerga, convida para outro voo, inspira uma aventura ainda não vivida e faz viver uma vontade de brincar, de 
experimentar o lúdico que nos desafia por questionar a seriedade cega que nos anula.

As intervenções realizadas dentro da investigação contribuíram para desmistificar a ideia de fantasia infantil como uma adaptação ao erro, concepção alicerçada sobre o pressuposto de que a criança fantasia simplesmente porque lhe faltam condições para satisfazer uma vontade, uma adaptação pela carência e não um mecanismo particular de ação. A visão tradicional naturaliza o fenômeno, o que por sua vez compromete o investimento nessa linguagem e contribui para a preservação da orientação meramente propedêutica nas instituições de Educação Infantil.

As professoras compreenderam a importância de educar para imaginação e encontraram meios para esse fim (GIRARDELLO, 2005). Identificamos conjuntamente que escutar as crianças é fundamental e utilizar dos elementos manifestos em suas falas e em outras expressões para o desenvolvimento das atividades é o modo de tornar essa escuta efetiva e construir os vínculos de confiança com as crianças (CORSARO, 2011).

A partir das falas das crianças foram construídas muitas histórias, ainda, que junto das professoras tivéssemos prévias de um roteiro para ser narrado e vivenciado. As crianças puderam mudar as direções, fazer novos finais, estruturar outros começos e construir histórias inteiras. Todas as histórias puderam ser experimentadas por meio de brincadeiras e jogos de fantasia, baseados nessas construções que podemos chamar de "histórias abertas" (RODARI, 1982). As histórias abertas contribuíram para abrir novos caminhos para a abordagem pedagógica nas duas instituições, melhorando a relação entre os sujeitos envolvidos e o imaginário infantil, alcançando inclusive, os lares das crianças, que contaram suas experiências e conquistaram o maior interesse de seus pais e responsáveis pelo estudo.

Para participar dos mundos das crianças foi preciso como afirma Bastide (1961, p. 154): “[...] penetrar além do círculo mágico que dela nos separa, em suas preocupações, suas paixões", foi necessário viver o lúdico. Nessas vivências de penetração nos territórios de magia construídos pelas crianças, percebemos que podemos contribuir muito mais com essas construções, tornando os espaços mais inspiradores, propondo desafios, mergulhando em histórias, transbordando o interesse de sermos parceiros nessa saga por descobrir e interpretar o mundo, e não meros juízes limitados a ficar do outro lado da fronteira exigindo que as crianças voltem para as terras da realidade.

O imaginário é também uma forma de comunicação com a criança. Tendo em vista a 
importância que a imaginação possui, o fato de não considerarmos as histórias provindas das crianças pode significar um ato de desvalorização e até rejeição para elas. Mas, se ao contrário soubermos escutá-las atentamente, como fazemos com os adultos ao julgar que têm algo importante a dizer, certamente as crianças se sentirão respeitadas e poderão estabelecer vínculos de confiança, o que renderá um rumo mais promissor para as relações (CORSARO, 2011). Neste sentido, esta investigação teve como objetivos principal a construção de vínculos de confiança entre os adultos e crianças investigados por meio do desenvolvimento de jogos de fantasia e atividades de aproximação entre os sujeitos.

\section{METODOLOGIA}

A partir de algumas leituras sobre as investigações de natureza empírica dentro das escolas, encontramos nos teóricos da investigação-ação uma gama de considerações muito profícuas para 0 trabalho. Optamos por esse tipo de metodologia que é considerado por alguns autores como um sinônimo de pesquisaação, porém, independente das diferenças que possam ser traçadas, utilizamos o termo investigação-ação, pois assim denominam a maioria dos autores utilizados neste estudo. Para Grabauska e Bastos (1998, p. 02):
A origem da investigação-ação está nos trabalhos de LEWIN (1946; 1952), com dinâmica de grupos, no sentido de integrar as minorias, especialmente étnicas, á sociedade nos Estados Unidos da América. Ao mesmo tempo, procurava estabelecer as bases para a cientificidade das ciências sociais, a partir de um trabalho empírico.

Grabauska e Bastos (1998) afirmam que é no trabalho do psicólogo alemão Kurt Lewin que se percebe os primeiros passos de uma nova concepção de investigação que busca outro status para as ciências sociais sem descartar a objetividade e validade do conhecimento. A proposta lewiana traz inicialmente a preocupação de integrar determinado grupo à sociedade, buscando meios de superar a situação de exclusão. Essas preocupações e estratégias são retomadas posteriormente dentro de um formato mais radicalmente focado na emancipação, no qual: "[...] têm lugar central os processos de inovação e transformação dinamizados por uma intervenção reflexiva, cientificamente informada e produtiva, geradora de conhecimentos teóricos e operatórios generalizáveis" (BENAVENTE; COSTA; MACHADO, 1990, p.11).

Benavente, Costa e Machado (1990) consideram que a investigação-ação 
representa uma análise sociológica, abordagem reflexiva sobre as relações sociais de intervenção, observação e produção de conhecimentos teóricos e operatórios, que são estabelecidas e modificadas durante o processo. A natureza empírica representa a possibilidade de transformar as realidades do contexto, e na perspectiva desta pesquisa se situa dentro da preocupação de repercutir na prática pedagógica uma maior valorização da fantasia infantil assim como a concepção de criança como ator social e a infância como categoria social de estatuto próprio.

A necessidade de intervenção se relaciona com as considerações de Martín e Mas (1994, p. 24):

Estamos convencidos
que nós professores
teremos que começar a
pensar sobre nosso
trabalho em termos
práticos, pois, é na
prática que tomam
corpo as possíveis
teorias e onde se
concretizam ou se
desfazem os grandes
princípios ideológicos
com que às vezes nós
enchemos a boca
(Traduçãonossa).

As próprias professoras afirmaram que além da explanação teórica é fundamental um caminho prático, já que a contextualização de uma nova gama de saberes consiste uma tarefa complexa. Além disso, a reflexão sobre a própria prática à luz de uma teoria representa a oportunidade de construir um olhar mais crítico que não seja apenas contemplado no período da pesquisa, mas, que possa repercutir e ser renovado ao longo da vida profissional das professoras.

$$
\text { Contreras-Domingo (1994, p. 14) }
$$

entende que a investigação-ação:

[...] não é somente uma metodologia. investigação-ação não é somente uma coleção de técnicas e recursos para obter dados. Em todo o caso, estas técnicas e recursos devem estar a serviço da filosofia que inspira a investigaçãoação. A investigaçãoação é uma forma de entender a prática docente segundo a qual tentamos melhorá-la sistematicamente,

buscando para isso entender melhor quais são os contextos e condicionantes da mesma. Não é somente uma ajuda para resolver os problemas da prática, mas é um processo para problematizar a prática, descobrir a natureza problemática da educação e para ao problematizá-la, reorganizar o sentido da mesma, assim como a avaliação de como deveria ser, ao que deveria aspirar (Tradução nossa).

Esse modo de compreender o trabalho docente e entender seus 
condicionantes não surge espontaneamente ou no vazio das relações de poder. Dessa forma, Benavente, Costa e Machado (1990, p.13) entendem que: "[...] a iniciativa ou encomenda formal não são neutras, nem o são os problemas e os grupos com que ela está relacionada". Há um problema comum que precisa também ser pensado coletivamente.

Como o método da investigação-ação propõe, intervimos com um roteiro (ação), observamos como ele é vivenciado pelas crianças (observação), escutamos os sujeitos e refletimos sobre o que julgam se interessar, o que desejam experimentar (reflexão) e a partir disso propomos uma experiência inédita (nova ação). Essas etapas do percurso estão relacionadas a descrição de Tripp (2005, p. 446): “A solução de problemas, por exemplo, começa com a identificação do problema, o planejamento de uma solução, sua implementação, seu monitoramento e avaliação de sua eficácia". Mais especificamente a afirmação de ContrerasDomingo (1994, p. 14):

A Investigação-ação constitui sempre um processo contínuo, em espiral, de açãoobservação-reflexãonova ação, etc. A analise da ação e a reflexão sobre ela, sobre os problemas que se apresentam à luz do que pretendemos, é sempre um processo sem fim (Tradução nossa).

O problema principal era a falta de compreensão e valorização da linguagem imaginativa das crianças nas instituições de Educação Infantil parceiras, percebido pelos pesquisadores e pelas próprias profissionais, que alegavam não saber bem os caminhos para contemplar as fantasias infantis em suas abordagens pedagógicas. Em resposta, a proposta de ação foi o desenvolvimento de diversas experiências de fantasia, a partir da valorização das crianças e suas culturas. A reflexão das ações ocorreu em paralelo às atividades e em momentos específicos de diálogo, levantamento e avaliação dos dados. As propostas de nova ação foram subsequentes à escuta da opinião das crianças em relação à intervenção assim como a consideração das professoras.

As professoras além de acompanhar as atividades, também opinaram e revelaram continuamente a repercussão gerada pelos roteiros desenvolvidos no decorrer das aulas, auxiliando ainda na compreensão das realidades das crianças além das intervenções da pesquisa e da própria instituição escolar, essas informações foram fundamentais para o estudo.

O envolvimento com os pais foi iniciado pelas próprias crianças que com particular maestria explicavam o que havia ocorrido nas intervenções e aguçavam a 
curiosidade desses sujeitos. Além disso, houve reuniões específicas sobre a investigação, assim como os encontros do próprio calendário escolar e os momentos dos pais e responsáveis levarem e buscarem as crianças nas instituições escolares. Junto a esses parceiros conversávamos sobre 0 brincar no lar, a importância da fantasia, contextos e laços sociais que fazem parte da vida das crianças.

De forma geral, todos os pais e responsáveis foram muito solícitos, alguns relataram a falta de tempo para uma participação mais ativa na escola e afirmaram ser necessária essa parceria, assim como a valorização da linguagem imaginativa infantil. Além disso, seus dizeres, muito contribuíram com o desenvolvimento do estudo em seus dois anos, a relação foi estreitada gradativamente e permitiu a ampliação da compreensão da linguagem imaginativa infantil, um dos objetivos da investigação. Todos os dados foram relatados por meio de diários de campo e aparelhos midiáticos, levantados durante as intervenções, entrevistas, reuniões e demais vivências com os diferentes sujeitos participantes.

A escolha metodológica se assentou muito bem sobre nossos anseios de contribuir para mudanças. A investigaçãoação permitiu uma relação muito estreita entre os sujeitos da pesquisa, de uma forma tão intensa que a parceria chegou a possibilitar espaço para confissões sobre os medos e angustias acerca da prática, as dificuldades com leitura de obras, com a busca de formação continuada, com o sistema, com os pais. Esta investigação faz parte de uma pesquisa maior, aprovada pelo Comitê de Ética da FCT/UNESP sob o número de inscrição na Plataforma Brasil: 13424213.8.0000.5402.

\section{RESULTADOS}

A partir das observações realizadas, das leituras e releituras dos diários de campo, análise dos dados em áudio, fotografia e vídeo, entrevistas, reuniões e conversas informais, foram identificados relevantes resultados da investigação. Os sujeitos envolvidos das duas instituições investigadas concordaram com os seguintes apontamentos:

- Alcançamos a ampliação e transformação na maneira de compreender a linguagem imaginativa infantil, especialmente por parte das professoras, pais e responsáveis;

- Construímos práticas educativas mais próximas dos interesses e necessidades das crianças e compartilhamos atividades voltadas ao desenvolvimento da imaginação entre pesquisadores, professoras, pais e responsáveis; 
- As crianças demonstraram maior interesse para com suas instituições escolares;

- As crianças passaram a participar mais ativamente das atividades escolares e demonstrar maior criatividade das crianças expressa durante o desenvolvimento de diferentes atividades dentro e fora da pesquisa, tanto nas instituições escolares quanto nos lares;

- Identificamos diferentes saberes sobre a linguagem imaginativa infantil, seu desenvolvimento, o papel da escola e da família na educação para a imaginação (GIRARDELLO, 2005), e procedimentos específicos para contemplar a linguagem imaginativa nas abordagens pedagógicas realizadas com as crianças, em especial, as histórias abertas (RODARI, 1982).

- Alcançamos uma maior aproximação entre as crianças, as professoras, pais e responsáveis, sobretudo, a compreensão mais valorativa do imaginário infantil por parte das professoras e maior participação dos pais e responsáveis nas brincadeiras de seus filhos ou netos.

\section{DISCUSSÃO}

Nas falas de cada sujeito pudemos identificar o reflexo das experiências, a intensidade de cada encontro alicerçado no mundo da fantasia, apresentado pelas crianças e admirado pelas Professoras, diretoras, coordenadoras, funcionárias, pais e responsáveis, adultos participantes que partilharam seus preciosos ganhos a partir deste estudo.

Dialogando com as professoras, refletimos que em paralelo a valorização da infância se encontra a valorização da própria atuação do professor, já que a relação pedagógica torna-se mais agradável quando as atividades realizadas são mais significativas para ambos os sujeitos, ao partirmos da criança e a alcançando efetivamente. Isso requer disposição para o aprendizado constante, assumir os desafios que as diferentes crianças trazem e aprender com elas novas formas de superação.

Fomos percebendo junto com as professoras que a complexidade das fantasias aumentava a cada encontro, assim como a quantidade de cenas e diálogos produzidos, o que exigia uma maior atenção para conseguir acompanhar essas experiências, transcrevêlas e analisá-las. De outro lado, as professoras percebendo o que parecia ser interessante, procuravam partilhar e refletir sobre o que viam e escutavam. Essa ação possibilitou um maior fortalecimento da parceria e uma constante atenção por parte delas às crianças.

Ao chegarmos às instituições, antes de entrarmos em sala, as professoras já contavam as novidades, destacando determinadas falas das crianças, 
apresentando dúvidas sobre a temática e propostas para o estudo. Algumas conversas aconteciam junto a todo o grupo, outras eram confissões particulares, desabafos em lugares e momentos reservados. Todas demonstraram a necessidade de um espaço maior de discussão entre os professores, como maneira de compartilhar descobertas e encontrar direções. Nas duas instituições, as diretoras foram consideradas por elas como boas dirigentes, além disso, também participaram deste estudo.

Além de sentirem-se beneficiadas pelo estudo, as professoras enalteceram a repercussão das atividades na vida das crianças, demonstrando que a principal comprovação da eficácia da proposta foi manifestada por elas, que demonstraram o novo sentido que a prática pedagógica pode encontrar quando o olhar infantil é entendido como um farol e não apenas um reflexo do universo adulto. De alguma forma, as professoras se sentiram amparadas, tiveram a possibilidade de experimentar uma nova experiência, de se permitir a uma proposta, de pesquisar. Além disso, puderam partilhar suas dificuldades, confessar os medos e se sentirem capazes de superar os constantes desafios.

Podemos acreditar que assim como as atividades da investigação foram desenvolvidas em outros momentos dentro das instituições durante o processo de investigação, essas experiências continuarão a ser proporcionadas às crianças que permanecerem ou que adentrarem as escolas investigadas, assim como as que vierem a compor as turmas assumidas pelas professoras participantes em outras possíveis instituições. Sabemos que as professoras têm a liberdade de continuar ou não trilhando os caminhos vivenciados, contudo, elas reivindicaram a preservação do vínculo, o que demonstra $\mathrm{o}$ interesse de manter $\mathrm{o}$ caminho e a potencialidade da proposta.

Aprendemos juntos e nos permitimos adentrar ao mundo da fantasia, sabemos que muito ainda precisa ser compreendido sobre essa temática. A imaginação não é uma linguagem simples, mas também as maneiras de valorizá-la não são um complexo inalcançável. A aproximação com as crianças e os mundos que constroem requer o distanciamento do olhar descrente acerca da seriedade com que fantasiam, assim como o avanço das práticas pedagógicas parece depender muito do recuo de nossas práticas adultocêntricas.

As professoras participantes desta investigação chegaram ao fim da pesquisa com a certeza de terem aprendido um pouco mais sobre as crianças a partir de diferentes encontros com elas, confessaram necessitar de avanços em muitos pontos de suas abordagens e afirmaram ter a disposição de buscá-las. Em todo o momento puderam 
expressar suas opiniões, dúvidas e críticas, assim como os demais sujeitos, essa liberdade sustentou a relação de cooperação que foi constante durante toda a pesquisa.

As contribuições dos pais e responsáveis também foram muito profícuas para o estudo, representaram uma importante fonte de saberes sobre as crianças, assim como uma devolutiva sobre as repercussões da pesquisa no lar, espaço onde não podemos acompanhar as crianças diretamente. Mesmo para os já participantes do estudo precursor, a pesquisa foi uma experiência inovadora, que superou as expectativas geradas no primeiro encontro, permitindo que os pais e responsáveis se sentissem e realmente fossem sujeitos da investigação, também responsáveis pelo processo.

No decorrer do estudo os pais e responsáveis buscaram momentos de partilhas conosco, expressando as mudanças que perceberam na vida de seus filhos ou netos a partir da investigação. Revelaram diversos fatos, como o aumento das atividades de faz de conta em casa, o maior desejo das crianças em ir à escola, a diminuição da timidez, a evolução da criatividade, maior aprendizado e diminuição do tempo que assistem televisão.

Além das reuniões e conversas informais, utilizamos um questionário já no final do estudo para identificar as opiniões dos pais e responsáveis. De um total de 170, $80 \%$ responderam (136 de 170 ), dos $20 \%$ restante (34), a metade desse o número (17) preferiu a expressão verbal por meio de entrevista ou conversas informais, o número restante (17) representou os que não deram um retorno sobre as questões apresentadas, o que não significa que não tenham apresentado devolutivas em outros momentos da investigação.

As falas de satisfação acerca do estudo foram muito motivadoras, e percebemos que o interesse dos pais e responsáveis pela pesquisa era algo também esperado pelas crianças, pois ao falar sobre suas experiências desejavam uma reação positiva. Algumas mães declararam que entenderam o sentido do estudo a partir de um momento como esse, ao render-se aos relatos dos filhos, dispondo-se a escutá-los, percebendo que para eles era muito importante sua participação.

Os pais e responsáveis afirmaram que a partir do início da pesquisa as crianças passaram a falar mais das rotinas vividas nas escolas, compartilhar suas histórias e jogos, e ainda, cobrar a contribuição deles em suas brincadeiras em casa. Para eles, após terem aceitado o desafio de dotar um novo olhar e assumir um novo proceder, a mudança das atitudes foi acontecendo gradativamente e as falas das crianças também se tornavam mais instigantes para eles a cada dia. Os 
roteiros foram evoluindo em complexidade, compreender melhor a linguagem imaginativa parecia cada vez necessário para acompanhar seus filhos ou netos.

Ao perceber que poderiam apresentar suas dúvidas, muitos pais e responsáveis fizeram questões bem pontuais, compartilhando casos do dia a dia, questionamentos e esperas acerca das crianças. Uma das mães da Instituição II afirmou se interessar pelo desenvolvimento da imaginação de sua filha e entendia que uma das possíveis contribuições seria por meio da disponibilização de brinquedos, que para ela era o modo mais fácil e eficaz. Refletimos juntos que isso não é bastante, é preciso se preocupar com os enredos, com as histórias que podem ser criadas, é preciso adentrar o brincar, propor desafios, motivar invenções, ir além dos materiais, manter-se interessado em escutar, estar disponível pra encenar e fantasiar.

A parceria firmada, o diálogo entre os diferentes contextos se consolidou conforme as sucessivas experiências. Sabemos que o contato não findará após o término do estudo devido o compromisso social e os resultados que ainda poderão ser compartilhados posteriormente pelos sujeitos.

Acreditamos que as crianças conquistaram um espaço mais qualificado para a construção de suas culturas e fantasias, tanto nas instituições de Educação Infantil investigadas quanto em seus lares. Esperamos que os pais e responsáveis continuem interessados em aprender sobre a infância e defendam a valorização das crianças como sujeitos sociais ativos, assim como as instituições escolares investigadas possam garantir um diálogo efetivo com as famílias e considerem as culturas familiares como conteúdos indispensáveis na educação das crianças.

Tivemos o privilégio de contribuir com uma cultura de encontro, de promover práticas de voz e de escuta, buscando qualificar as formas de escutar as crianças sem esquecer de seus preceptores, que de clientes distantes devem se tornar parceiros dispostos, que de responsáveis ou simples questionadores devem tornar-se também pesquisadores da infância, desbravadores de seus mundos, aprendizes das crianças pelo bem delas, de suas escolas e de suas famílias.

Os resultados foram identificados nas duas instituições investigadas, apontados e confirmados pelos sujeitos participantes. As crianças foram as grandes difusoras da pesquisa, souberam demonstrar a riqueza de suas fantasias, de um modo que não poderíamos expressar por nós mesmos. A mobilização das professoras e dos pais como já expresso foi resultante das repercussões demonstradas pelas crianças. Acreditamos que o maior espaço e respeito para com suas 
fantasias, conquistado por elas e para elas, possibilitará ainda mais resultados.

As falas de todos os sujeitos participantes confirmaram a importância da temática e necessidade de um maior investimento na educação para a imaginação. Em especial, os relatos de pais e professoras sobre a aproximação vivida entre eles e as crianças a partir das intervenções deste estudo, essas descrições demonstram que a valorização do imaginário infantil é um importante caminho para a compreensão da infância e melhoria das relações entre adultos e crianças.

\section{CONCLUSÃO}

As professoras das instituições investigadas afirmavam entender a necessidade de educar para a imaginação (GIRARDELLO, 2005), mas não se sentiam preparadas para desempenhar uma abordagem pedagógica pautada no imaginário infantil, diziam que seus processos de formação inicial não contemplaram esses saberes e que faltavam momentos de formação continuada sobre a linguagem imaginativa infantil em seus municípios. Elas demonstraram o interesse de conhecer a temática e aprofundar seus conhecimentos sobre a criança e a infância, para tal fim, utilizamos os teóricos da Sociologia da Infância e as contribuições dos estudos do
Professor Paul L. Harris sobre a imaginação na infância.

A realização desta investigação foi beneficiada pelos vínculos já firmados durante a pesquisa precursora, a partir do fortalecimento da relação de cooperação entre pesquisadores e professores foi alcançado um número maior de sujeitos, crianças, pais, responsáveis e outros profissionais das duas instituições investigadas vivenciaram um processo interventivo e continuado de aprofundamento dos saberes e das experiências da atividade imaginativa infantil.

A metodologia escolhida permitiu o desenvolvimento de intervenções semanais alicerçadas nas fantasias infantis. Nessas intervenções, foram desenvolvidas diversas atividades pautadas na linguagem imaginativa das crianças, por meio de brincadeiras e jogos de fantasia, atividades artísticas e criativas, contação e construção de histórias.

O espaço para a vivência das infantis foi ampliado nas duas instituições participantes. As diversas atividades realizadas contribuíram para ampliação da experiência do imaginário para os diferentes sujeitos. As crianças puderam vivenciar e criar fantasticamente, as professoras acompanharam as crianças e aprenderam com elas sobre a imaginação na infância, as demais profissionais das duas instituições 
puderam acompanhar o processo e perceber as repercussões geradas nas vidas dos participantes, os pais e responsáveis foram alcançados por seus filhos e netos, as crianças conquistaram o interesse deles por suas fantasias e pelo estudo a partir de suas falas e convites para participação em suas brincadeiras.

As experiências vividas produziram uma maior gama de saberes sobre a linguagem imaginativa na infância. Os adultos participantes perceberam que é importante motivar e oportunizar as fantasias infantis, já que essa atividade é uma base para o processo de inteligibilidade das crianças (SARMENTO, 2004), não se resume a infância, é uma linguagem fundamental que é desenvolvida ao longo de toda a vida (HARRIS, 2005).

É comum que ao acompanhar as crianças fantasiando nos admiremos com suas expressões, mas a devida valorização dessa linguagem requer $o$ colocar-se a disposição de seus roteiros, sem invadir suas cenas ou gritar das coxias, mas, explicitar que levamos a sério suas composições, que nos interessamos pelos roteiros, por suas falas, suas artes, suas culturas.

Dispor-se às crianças é um desafio aos profissionais da Educação Infantil, já que o comum é dispor-lhes o que se acha interessante sem considerar efetivamente suas opiniões. Ir contra a essa corrente não é uma tarefa fácil, mas independente das águas turbulentas que enfrentamos e ainda enfrentaremos no compartilhar deste estudo, conseguimos enxergar "terra a vista", e desvendamos um pouco do mapa dos tesouros resguardados nas ilhas das crianças situadas além dos mares que banham os continentes adultos, um pouco mais frios e cabais.

Nas terras da fantasia percebemos a fertilidade no cultivo de histórias, no controle de lavouras e pomares, de hortaliças e frutos cheios de cores e sabores, mudando de formas, assumindo outras fragrâncias, alcançando outros horizontes, regados por inesgotáveis fontes. Foram a partir delas que enxergamos nossos desertos, nossos secos sertões, as rachaduras em nossos duros solos, tostados pela luz de lâmpadas artificiais, nossos vícios em correr sem nunca parar, de dormir e pouco sonhar.

\section{REFERÊNCIAS}

BARBOSA, Maria Carmen Silveira. Legislação e propostas curriculares: há lugar para a imaginação?. In: SEMINÁRIO EDUCAÇÃO, IMAGINAÇÃO E AS LINGUAGENS ARTÍSTICOSCULTURAIS, 1. , 2005, Criciúma. Anais eletrônicos... Criciúma: UNESC, 2005. Disponível em:http://www.gedest.unesc.net/seilacs/isei lac.pdf.>. Acesso em: 17 mar. 2012. http://dx.doi.org/10.1590/S010173302007000300020 
BARBOSA, Maria Carmen Silveira. Culturas escolares, culturas de infância e culturas familiares: as socializações e a escolarização no entretecer destas culturas. Educação e Sociedade, Campinas, v. 28, n.100, p. 10591083, out. 2007.

BASTIDE, Roger. As "Trocinhas" do Bom Retiro. In: FERNANDES, Florestan. Folclore e mudança social na cidade de São Paulo. São Paulo: Anhambi, 1961.

BENAVENTE, Ana; COSTA, Antônio Firmino da; MACHADO, Fernando Luís. Práticas de Mudança e de Investigação: conhecimento e intervenção na escola primária. Revista Crítica de Ciências sociais, v. 29, p. 1-28, fev. 1990.

CONTRERAS-DOMINGO, J. ¿Como se hace?. Cuadernos de Pedagogia, Barcelona, n. 224, p. 14-19, abr. 1994.

CORSARO, William A. Sociologia da Infância. 2. ed. Porto Alegre: Artmed, 2011.

GIRARDELLO, Gylka. A Imaginação Infantil e as histórias da TV. Construir Notícias, Recife, p. 33-36, mar. 2005.

GRABAUSKA, Claiton José; BASTOS, Fábio da Purificação de. Investigação-ação educacional: possibilidades críticas e emancipatórias na prática educativa. Heuresis, v. 1, n. 2, p. 1-12, 1998.

HARRIS, Paul L. El funcionamento de la imaginación. 1. ed. Buenos Aires: Fondo de Cultura Económica, 2005.

MARTÍN, Sebastián Rodríguez; MAS, José Francisco Murillo. Una experiencia sobre participación de alumnos. Cuadernos de Pedagogia, Barcelona, n.. 224, p. 24-28, abr. 1994.

RODARI, Gianni. Gramática da fantasia. 7. ed. São Paulo: Summus, 1982.

SARMENTO, Manuel Jacinto. As Culturas da infância nas encruzilhadas da segunda modernidade. In: SARMENTO, Manuel Jacinto; CERISARA, Ana Beatriz. Crianças e miúdos: perspectivas sociopedagogicas da infância e educação. Porto: ASA, 2004. 256 p.

Recebido para publicação em 19/08/2015 Revisado em 03/09/2015

Aceito em 08/09/2015 